\title{
The Thermochemistry of 2,4-Pentanedione Revisited: Observance of a Nonzero Enthalpy of Mixing between Tautomers and Its Effects on Enthalpies of Formation
}

\author{
Manuel Temprado, ${ }^{\dagger}$ Maria Victoria Roux, ${ }^{\dagger}$ Patamaporn Umnahanant, Hui Zhao, and \\ James S. Chickos* \\ Department of Chemistry and Biochemistry, University of Missouri-St. Louis, St. Louis, Missouri 63121
}

Received: March 23, 2005; In Final Form: May 6, 2005

\begin{abstract}
The enthalpies of formation of pure liquid and gas-phase (Z)-4-hydroxy-3-penten-2-one and 2,4-pentanedione are examined in the light of some more recent NMR studies on the enthalpy differences between gas-phase enthalpies of the two tautomers. Correlation gas chromatography experiments are used to evaluate the vaporization enthalpies of the pure tautomers. Values of $(51.2 \pm 2.2)$ and $(50.8 \pm 0.6) \mathrm{kJ}^{\circ} \mathrm{mol}^{-1}$ are measured for pure 2,4-pentanedione and (Z)-4-hydroxy-3-penten-2-one, respectively. The value of $(50.8 \pm 0.6) \mathrm{kJ} \cdot \mathrm{mol}^{-1}$ can be contrasted to a value of $(43.2 \pm 0.2) \mathrm{kJ} \cdot \mathrm{mol}^{-1}$ calculated for pure $(Z)$-4-hydroxy-3-penten-2-one when the vaporization enthalpy is measured in a mixture of tautomers. The difference is attributed to an endothermic enthalpy of mixing that destabilizes the mixture relative to the pure components. Calculation of new enthalpies of formation for (Z)-3-hydroxy-3-penten-2-one and 2,4-pentanedione in both the gas, $\Delta_{\mathrm{f}} H^{\circ} \mathrm{m}(\mathrm{g})=$ $(-378.2 \pm 1.2)$ and $(-358.9 \pm 2.5) \mathrm{kJ} \cdot \mathrm{mol}^{-1}$, respectively, and liquid phases, $\Delta_{\mathrm{f}} H_{\mathrm{m}}^{\circ}(\mathrm{l})=(-429.0 \pm 1.0)$ and $(-410.1 \pm 1.2) \mathrm{kJ} \cdot \mathrm{mol}^{-1}$, respectively, results in enthalpy differences between the two tautomers both in the liquid and gas phases that are identical within experimental error, and in excellent agreement with recent gas-phase NMR studies.
\end{abstract}

\section{Introduction}

2,4-Pentanedione forms complexes with a variety of metal ions. Its enthalpy of formation is a crucial property in the evaluation of the enthalpies of formation of these complexes. Unlike most organic compounds that exist predominately in one form, two tautomeric forms, 2,4-pentanedione and (Z)-3-hydroxy-3-penten-2-one, coexist with the latter predominating at equilibrium. The presence of this equilibrium complicates the evaluation of the thermodynamic properties of the two pure constituents. This article examines some of these properties in light of recent measurements and reports some additional experimental results that elucidate the thermochemistry of the processes involved in the equilibrium. To avoid any confusion, the term acetylacetone will be used when referring to the equilibrium mixture, and the terms 2,4-pentanedione and (Z)-4-hydroxy-3-penten-2-one will be used to refer to each respective tautomer.

The enthalpy of formation of acetylacetone in the liquid phase has been measured several times. ${ }^{1-4}$ Not all measurements are in agreement. Measurements by Nicholson in $1957^{3}$ were confirmed more recently by Hacking and Pilcher. ${ }^{4}$ Since the Nicholson determination, $\Delta_{\mathrm{f}} H^{\circ}{ }_{\mathrm{m}}(1,298.15 \mathrm{~K})=(-423.8 \pm 1.6)$ $\mathrm{kJ} \cdot \mathrm{mol}^{-1}$, was corrected for approximately $2 \%$ xylene present as an impurity, the value reported by Hacking and Pilcher, $(-425.5 \pm 1.0) \mathrm{kJ} \cdot \mathrm{mol}^{-1}$, has generally been accepted as the enthalpy of formation of the equilibrium mixture of the pure liquid.

The enthalpy of vaporization of acetylacetone has also been measured several times. ${ }^{5-11}$ The resulting values, in chronologi-

* Address correspondence to this author. Phone: +1-314-516-5377. Fax: +1-314-516-5342. E-mail: jsc@umsl.edu.

On leave from the Instituto de Química Física "Rocasolano", Serrano 119, Madrid 28006, Spain. cal order, are summarized in Table 1. Good agreement is found for most of the recent measurement if the experimental data are adjusted to $T=298.15 \mathrm{~K}$. Equation 1 was used for this purpose. The term $C_{\mathrm{pl} \mathrm{m}}$ represents the heat capacity of the liquid, which was estimated by group additivity. ${ }^{12}$ Since the heat capacity of the enol and diketo forms estimate slightly differently, a weighted average (see footnote $a$ of Table 1) was used in the adjustments.

$$
\begin{aligned}
& \Delta_{\mathrm{l}}^{\mathrm{g}} H_{\mathrm{m}}(298.15 \mathrm{~K}) / \mathrm{kJ} \mathrm{mol}^{-1}=\Delta_{\mathrm{l}}^{\mathrm{g}} H_{\mathrm{m}}\left(T_{\mathrm{m}}\right)+ \\
& {\left[\left(10.58+0.26 C_{\mathrm{pl} \mathrm{m}}\right)\left(T_{\mathrm{m}}-298.15\right)\right] / 1000}
\end{aligned}
$$

Hacking and Pilcher have used the calorimetric vaporization enthalpy of Irving and Wadsö ${ }^{8}$ to correct the condensed phase enthalpy of formation of liquid acetylacetone to the gas phase. A reason for choosing this value was based on the experimental conditions that Irving and Wadsö employed for their measurements. The calorimetric measurements were performed by using a trace of added concentrated sulfuric acid for the purpose of catalyzing diketo-enol tautomerism. The presence of sulfuric acid ensured a constant composition of diketo and enol forms during vaporization. The enol is more volatile than the diketo form and since the concentration of the enol predominates at equilibrium in the liquid phase, $(81.4 \%$ enol: $18.6 \%$ diketo $),{ }^{13-15}$ the composition of the vapor is highly enriched in enol. Irving and Wadsö concluded that their vaporization enthalpy measurements, $(41.8 \pm 0.1) \mathrm{kJ} \cdot \mathrm{mol}^{-1}$, referred to the process:

$$
\mathrm{C}_{5} \mathrm{H}_{8} \mathrm{O}_{2} \text { (liquid, } 81.4 \% \text { enol) } \rightarrow \mathrm{C}_{5} \mathrm{H}_{8} \mathrm{O}_{2} \text { (gas, } 93.3 \% \text { enol) }
$$

From the thermochemical cycle given in Figure 1 and the 72 enthalpy difference between the liquid forms of the diketone 73 and enol, $(-11.3 \pm 0.4) \mathrm{kJ} \cdot \mathrm{mol}^{-1}, 13$ and the gas forms of the 
TABLE 1: A Summary of the Vaporization Enthalpies Measured for Acetylacetone ${ }^{a}$

\begin{tabular}{|c|c|c|c|c|c|}
\hline $\begin{array}{c}\Delta_{\mathrm{l}}^{\mathrm{g}} H_{\mathrm{m}}\left(T_{\mathrm{m}}\right) / \\
\mathrm{kJ} \mathrm{mol}^{-1}\end{array}$ & $\begin{array}{c}T_{\mathrm{m}} / \\
\mathrm{K}\end{array}$ & $\begin{array}{c}\Delta C_{\mathrm{pl} \mathrm{m}} \Delta T / \\
\mathrm{kJ} \mathrm{mol}^{-1}\end{array}$ & $\begin{array}{c}\Delta_{\mathrm{l}}^{\mathrm{g}} H_{\mathrm{m}}(298.15 \mathrm{~K}) / \\
\mathrm{kJ} \mathrm{mol}^{-1}\end{array}$ & method & ref \\
\hline 36.14 & 417.1 & $8.1(7.7)$ & $44.2(43.8)$ & vapor pressure apparatus & 5 \\
\hline 38.97 & 328.8 & $2.1(2.0)$ & $41.1(41.0)$ & ebulliometrically & 6 \\
\hline 38.80 & 307.3 & $0.6(0.6)$ & $39.4(39.4)$ & vapor pressure apparatus & 7 \\
\hline 41.8 & 298.2 & & 41.8 & calorimetry & 8 \\
\hline 39.42 & 347.5 & $3.4(3.2)$ & $42.8(42.6)$ & isoteniscope & 9 \\
\hline 27.2 & NA & & & isoteniscope & 10 \\
\hline 48.12 & 366.7 & $4.7(4.4)$ & $52.8(52.5)$ & isoteniscope & 11 \\
\hline
\end{tabular}

${ }^{a}$ A value of $220.5 \mathrm{~J} \cdot \mathrm{mol}^{-1} \cdot \mathrm{K}^{-1}$ was used for $C_{\mathrm{pl} \mathrm{m}}\left\{(\right.$ enol, mol fraction: 0.814$), C_{\mathrm{pl} \mathrm{m}}=223.9$; $($ diketone, mol fraction: 0.186$)$ : $C_{\mathrm{pl} \mathrm{m}}=$ $\left.204.7 \mathrm{~J} \cdot \mathrm{mol}^{-1} \cdot \mathrm{K}^{-1}\right\}$; values in parentheses are results calculated by using the recommended experimental value of $208.2 \mathrm{~J} \cdot \mathrm{mol}-1 \cdot \mathrm{K}^{-1}$. ${ }^{-2}$

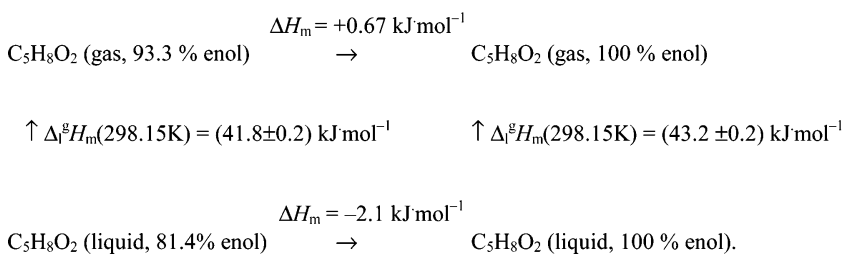

Figure 1. The thermochemical cycle used by Irving and Wadsö to calculate the vaporization enthalpy of (Z)-4-hydroxy-3-penten-2-one.

two tautomers, $\left.(-10.0 \pm 0.8) \mathrm{kJ} \cdot \mathrm{mol}^{-1}\right),{ }^{16}$ available at the time, a value of $43.2 \mathrm{~kJ} \cdot \mathrm{mol}^{-1}$ was calculated for the vaporization enthalpy of pure enol. The enthalpy difference between the two tautomeric forms was available from previous studies of the temperature dependence of the equilibrium constant between the two forms in the neat liquid. ${ }^{13}$

Using the Irving and Wadsö vaporization enthalpy, the concentrations of diketo and enol forms at equilibrium, and the enthalpy difference between the diketo and enol forms in both the liquid and gas phases, Hacking and Pilcher calculated the enthalpy of formation of pure liquid and gas-phase enol as $(-427.6 \pm 1.1)$ and $(-384.4 \pm 1.3) \mathrm{kJ} \cdot \mathrm{mol}^{-1}$, respectively. The enthalpy of formation of 2,4-pentanedione in the liquid and gas phases could be calculated from the enthalpy of enolization in the gas and liquid phase. The enthalpy of enolization in the gas phase available to Hacking and Pilcher at the time was $(-10.0 \pm 0.8) .{ }^{16}$ This value was also measured by the temperature dependence of the equilibrium constant in the gas phase by infrared spectroscopy. This resulted in values of $(-416.3 \pm 1.1)$ and $(-374.4 \pm 1.3) \mathrm{kJ} \cdot \mathrm{mol}^{-1}$, respectively, for 2,4-pentanedione. The thermochemical scheme used by Hacking and Pilcher is illustrated in Figure 2.

It is significant to point out that the enthalpy difference between the enol and diketone form, as measured by the temperature dependence of the equilibrium constant of the liquid phase, is actually a sum of the enthalpy of enolization and the enthalpy of intermolecular interactions between the enol and diketone forms. The enthalpy of intermolecular interaction between the two tautomers will be referred to as the enthalpy of mixing, $\Delta_{\mathrm{e}, \mathrm{k}} H_{\mathrm{mix}}$. An examination of the experimental liquid and gas-phase enthalpies of enolization available at the time reveals that they are within experimental error of each other. Thus $\Delta_{\mathrm{k}, \mathrm{e}} H_{\mathrm{mix}}=0$, justifying Hacking and Pilcher's use of the enthalpy of enolization, $\Delta H_{\text {diketo/enol }}$, as the difference between the enthalpies of the two liquid tautomers.

The enthalpy difference between the two tautomers of acetylacetone in both the liquid and gas phase has been measured a number of times. ${ }^{13,16-28}$ Table 2 provides a chronological summary of the enthalpy values reported in the literature for the enolization of acetylacetone. Investigations reported before $1950^{27,28}$ with bromine titration for analysis have not been included in the table. Several things become apparent

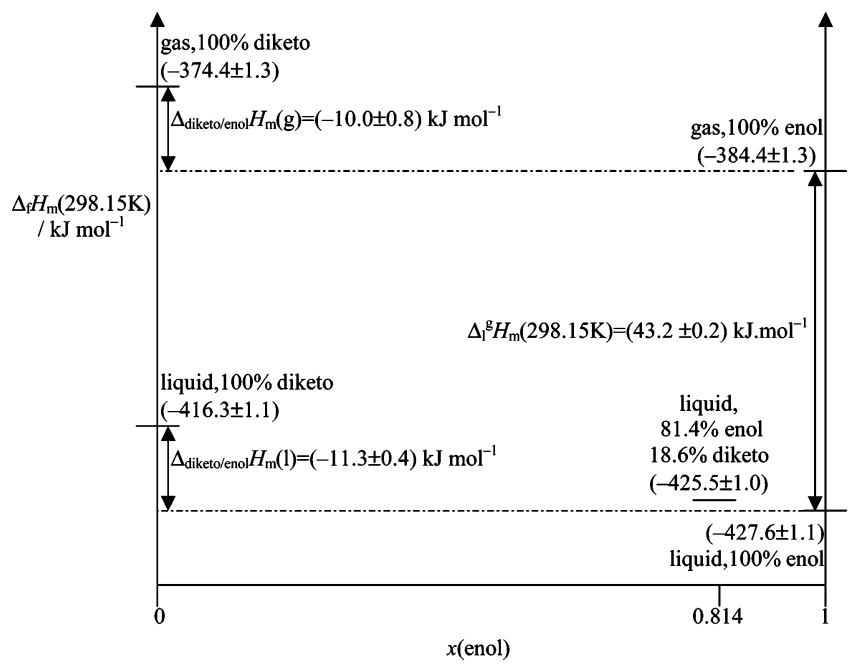

Figure 2. The thermochemical scheme used by Hacking and Pilcher to calculate the enthalpy of formation of of (Z)-4-hydroxy-3-penten2-one and 2,4-pentanedione.

upon examination of these measurements. There appears to be excellent agreement regarding the enthalpy difference between the diketo and enol forms in the pure liquid. The mean value of the condensed phase results reported in Table 2 is $(-11.7 \pm 0.3) \mathrm{kJ} \cdot \mathrm{mol}^{-1}$, in excellent agreement with the value used by Irving and Wadsö and Hacking and Pilcher.

Both spectroscopic and chemical methods have been used to determine the enthalpy of tautomerization in the gas phase. Unlike the condensed phase studies, agreement between methods is less than satisfactory. The values in the table appear to segregate into two groups, one group centered around $-18 \mathrm{~kJ} \cdot \mathrm{mol}^{-1}$ and the other around $-9 \mathrm{~kJ} \cdot \mathrm{mol}^{-1}$. If the correct value for the enthalpy of gas-phase keto-enol tautomerism is the lower of the two sets of values, than the enthalpies of formation calculated by Hacking and Pilcher for the pure liquids remain valid within the experimental uncertainty associated with these measurements. The enthalpy of keto-enol tautomerism associated with the most recent studies in the gas phase, however, suggests that some revision of the enthalpies of formation of both gaseous and liquid 2,4-pentanedione and (Z)-3-hydroxy-3-penten-2-one may be necessary.

An enthalpy of tautomerism of approximately $-18 \mathrm{~kJ} \cdot \mathrm{mol}^{-1}$ in the gas phase suggests a nonzero enthalpy of mixing term in the liquid phase to account for a value of $(-11.7 \pm 0.3)$ $\mathrm{kJ} \cdot \mathrm{mol}^{-1}$. Unless there are some peculiar destabilizing intermolecular interactions within a given tautomer in the liquid, an enthalpy of mixing, $\Delta_{\mathrm{k}, \mathrm{e}} H_{\text {mix }}$, of approximately $+6 \mathrm{~kJ} \cdot \mathrm{mol}^{-1}$ is required to reduce the gas-phase value to the value observed in the liquid phase. This calls into question the enthalpy of formation of pure liquid enol and diketone as calculated by Hacking and Pilcher. 
TABLE 2: A Summary of the Enthalpy Differences Measured between 2,4-Pentanedione and (Z)-3-Hydroxy-3-penten-2-one in the Liquid and Gas Phase ${ }^{a}$

\begin{tabular}{|c|c|c|c|c|c|}
\hline $\begin{array}{c}\Delta H_{\text {diketo/enol }}\left(T_{\mathrm{m}}\right)_{\text {liq }} / \\
\mathrm{kJ} \mathrm{mol}^{-1}\end{array}$ & $\begin{array}{c}T_{\mathrm{m}} / \\
\mathrm{K}\end{array}$ & $\begin{array}{c}\Delta H_{\text {diketo/enol }}\left(T_{\mathrm{m}}\right)_{\text {gas }} l \\
\mathrm{~kJ} \mathrm{~mol}^{-1}\end{array}$ & $\begin{array}{c}T_{\mathrm{m}} / \\
\mathrm{K}\end{array}$ & method & ref \\
\hline \multirow[t]{2}{*}{-11.7} & 303 & & & NMR & 17 \\
\hline & - & -17.0 & 422 & photoelectron spectroscopy & 18 \\
\hline-11.8 & 394.5 & -19.5 & 409 & NMR & 19 \\
\hline \multirow{3}{*}{$-11.7 \pm 1.3$} & 311 & & & NMR & 20 \\
\hline & & -18.0 & 388 & UV & 21 \\
\hline & & $-7.5 \pm 1.5$ & 373 & photoelectron spectroscopy & 22 \\
\hline$-11.9 \pm 0.8$ & 306 & -16.3 & & NMR & $\begin{array}{l}23 \\
24,21\end{array}$ \\
\hline \multirow[t]{4}{*}{-11.3} & & & & NMR & 13 \\
\hline & & -7.8 & 273 & bromination & 25 \\
\hline & & -9.2 & & isothermal distillation & 26 \\
\hline & & $-10.0 \pm 0.8$ & 386 & IR & 16 \\
\hline
\end{tabular}

${ }^{a}$ Enthalpy differences measured by the temperature dependence of the equilibrium constant.

An independent measurement of the vaporization enthalpy of pure enol would provide a positive test for a nonzero enthalpy of mixing term. If the acetylacetone mixture is destabilized as a result of a positive enthalpy of mixing, the vaporization enthalpy of the enol measured in this mixture should be attentuated by this amount from the value measured for a pure sample of (Z)-3-hydroxy-3-penten-2-one (I), eq 3. While an endothermic enthalpy of mixing between two polar molecules may seem surprising, the enthalpy of mixing of ketones with alcohols is frequently endothermic. ${ }^{29}$

$$
\begin{aligned}
& \Delta_{1}^{\mathrm{g}} H_{\mathrm{m}}(298.15 \mathrm{~K})(81.4 \% \text { enol, } 18.6 \% \text { diketo })= \\
& \Delta_{\mathrm{l}}^{\mathrm{g}} H_{\mathrm{m}}(298.15 \mathrm{~K})(100 \% \text { enol })-0.186 \Delta_{\text {keto/enol }} H_{\mathrm{m}}+ \\
& \Delta_{\mathrm{k}, \mathrm{e}} H_{\text {mix }}
\end{aligned}
$$

Correlation gas chromatography is an ideal method for determining the vaporization enthalpy of a pure material even though the material of interest may be present in a mixture. In the case of a dynamic equilibrium, all that is required for measurement is that the components in the mixture not equilibrate during the chromatography. In the absence of equilibration, the vaporization enthalpy of the pure material is obtained. A study of the vaporization enthalpy of the two tautomers, measured as pure liquids, is reported below.

\section{Experimental Section}

The compounds studied were all obtained from commercial vendors in high chemical purity $(98+\%)$. The gas chromatograph used to measure retention times was an HP 5980 Series II instrument equipped with a split-splitless capillary injection port and a FID detector. A split ratio of approximately 50:1 was used. A $30 \mathrm{~m} \mathrm{SPB-5}$ capillary column was used for the analyses. The retention times were recorded to three significant figures following the decimal point on an HP 3356 Series II integrator. The solvent used was either methylene chloride or methanol. At temperatures below $100{ }^{\circ} \mathrm{C}$, the solvent used was retained. Methane was bubbled into the solution just prior to injection and was used as the nonretained reference. The retention time of methane was used to determine the dead volume of the column. Adjusted retention times, $t_{\mathrm{a}}$, were calculated by subtracting the retention time of methane from the retention time recorded for each analyte. At the higher temperatures the retention time of the solvent was used as the nonretained reference. Column temperatures were controlled by the instrument and monitored with a Fluke $51 \mathrm{~K} / \mathrm{J}$ thermometer. All correlation gas chromatography experiments were performed in duplicate to confirm reproducibility. The results of only one experiment are reported below. GC-MS experiments were performed on an HP 5988 A instrument. The methods and procedures used to determine the enthalpy of vaporization and vapor pressures have been previously described in the literature $^{31}$ The temperature dependence of retention time of the mixtures employed in this study are provided as Supporting Information.

The vaporization enthalpies of 4-hydroxyacetophenone, methyl $p$-hydroxybenzoate, and 2,2,4,4-tetramethylcyclobutanedione were calculated by subtracting the fusion enthalpy adjusted to $T=298.15 \mathrm{~K}$ from the experimental sublimation enthalpy also adjusted to $T=298.15 \mathrm{~K}$. The following equations, shown to provide reliable temperature adjustments, ${ }^{32}$ were used to adjust sublimation and fusion enthalpies to $T=298.15 \mathrm{~K}$ :

$$
\begin{gathered}
\Delta_{\text {fus }} H_{\mathrm{m}}(298.15 \mathrm{~K})=\Delta_{\text {fus }} H_{\mathrm{m}}+\left[0.15 C_{\mathrm{p}, \mathrm{m}}(\mathrm{cr})-0.26 C_{\mathrm{pl} \mathrm{m}}-\right. \\
\left.9.83 \mathrm{~J} \cdot \mathrm{K}^{-1} \cdot \mathrm{mol}^{-1}\right]\left(T_{\text {fus }}-298.15 \mathrm{~K}\right) / 1000 \\
\Delta_{\text {vap }} H_{\mathrm{m}}(298.15 \mathrm{~K}) / \mathrm{kJ} \cdot \mathrm{mol}^{-1}=\Delta_{\text {sub }} H_{\mathrm{m}}(298.15 \mathrm{~K})- \\
\Delta_{\text {fus }} H_{\mathrm{m}}(298.15 \mathrm{~K})
\end{gathered}
$$

Fusion enthalpies of $p$-hydroxyacetophenone and 2,2,4, 203 4-tetramethylcyclobutanedione were measured on a Perkin- 204 Elmer DSC-7 at $5 \mathrm{~K} \mathrm{~min}^{-1}$. The calibration of the instrument 205 was checked by using an indium standard. Each analysis was performed at least three times. Values of $(18.0 \pm 0.2)$ and $(22.9 \pm 0.6) \mathrm{kJ} \cdot \mathrm{mol}^{-1}$ at onset temperatures, $T_{\text {fus }}=383$ and $386.9 \mathrm{~K}$, were measured for 4-hydroxyacetophenone and 2,2,4, 4-tetramethylcyclobutanedione, respectively. Details regarding the adjustments from experimental temperatures of measurement to $T=298.15 \mathrm{~K}$ with eqs 4 and 5 are provided in the Supporting Information. A summary of the vaporization enthalpies used in this study is provided in Table 3. Specific details and literature references are provided as Supporting Information.

The vaporization enthalpies of $o$ - and $p$-hydroxyacetophenone and methyl $p$-hydroxybenzoate, used as standards in the work, were also evaluated in separate correlations. Details for these evaluations are also are provided as Supporting Information.

\section{Results and Discussion}

Correlation gas chromatography is an ideal method for 221 determining the vaporization enthalpy of a pure material even 222 though the material of interest may be present in a mixture. 223 This has recently been demonstrated in the determination of 224 the vaporization enthalpy of acetoin, which exists in equilibrium 225 with a series of stereoisomeric dimers. ${ }^{32}$ All that is required is 226 a demonstration that the rate of equilibration is slow relative to 227 10 226
227 . .

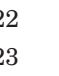
.  
TABLE 3: A Summary of the Literature Values Used as Vaporization Enthalpy Standards ${ }^{a}$

\begin{tabular}{cll} 
& $\begin{array}{c}\Delta_{\mathrm{l}}^{\mathrm{g}} \mathrm{H}_{\mathrm{m}}(298 \mathrm{~K}) / \\
\mathrm{kJ} \mathrm{mol}^{-1}\end{array}$ & \multicolumn{1}{c}{ comments } \\
\hline ref compds for enols & & single value \\
$\mathrm{C}_{4} \mathrm{H}_{8} \mathrm{O}_{2}$ (3-hydroxy-2-butanone) & $48.7 \pm 0.4$ & ave of 2 values \\
$\mathrm{C}_{5} \mathrm{H}_{10} \mathrm{O}_{3}$ (ethyl 2-hydroxypropanoate) & $52.5 \pm 3.0$ & ave of 2 values \\
$\mathrm{C}_{6} \mathrm{H}_{12} \mathrm{O}_{2}$ (4-hydroxy-4-methyl-2-pentanone) & $52.3 \pm 1.4$ & single value \\
$\mathrm{C}_{6} \mathrm{H}_{12} \mathrm{O}_{2}$ (ethyl 3-hydroxybutanoate) & $55.9 \pm 0.6$ & this work, see Supporting Information \\
$\mathrm{C}_{8} \mathrm{H}_{8} \mathrm{O}_{3}$ (o-hydroxyacetophenone) & $59.6 \pm 0.6$ & this work, see Supporting Information \\
$\mathrm{C}_{8} \mathrm{H}_{8} \mathrm{O}_{3}$ (p-hydroxyacetophenone) & 82.5 & ave of 3 alues \\
$\mathrm{C}_{8} \mathrm{H}_{8} \mathrm{O}_{3}$ (methyl o-hydroxybenzoate) & $62.0 \pm 1.8$ & this work \\
$\mathrm{C}_{8} \mathrm{H}_{8} \mathrm{O}_{3}$ (methyl p-hydroxybenzoate) & 83.1 & single value \\
$\mathrm{C}_{8} \mathrm{H}_{16} \mathrm{O}_{3}$ (ethyl 3-hydroxyhexanoate) & $61.9 \pm 0.6$ & single value \\
$\mathrm{C}_{9} \mathrm{H}_{10} \mathrm{O}_{3}$ (ethyl $o$-hydroxybenzoate) & 66.5 & \\
ref compds for diketones & & ave of 2 values \\
$\mathrm{C}_{4} \mathrm{H}_{6} \mathrm{O}_{2}$ (2,3-butanedione) & $39.0 \pm 0.6$ & single value \\
$\mathrm{C}_{6} \mathrm{H}_{4} \mathrm{O}_{2}$ (1,4-benzoquinone) & 53.4 & single value \\
$\mathrm{C}_{6} \mathrm{H}_{10} \mathrm{O}_{2}$ (2,5-hexanedione) & 57.5 & two values reported \\
$\mathrm{C}_{8} \mathrm{H}_{12} \mathrm{O}_{2}$ (2,2,4,4-tetramethylcyclobutanedione) & $54.2 \pm 0.3$ &
\end{tabular}

${ }^{a}$ Details and references are given as Supporting Information.

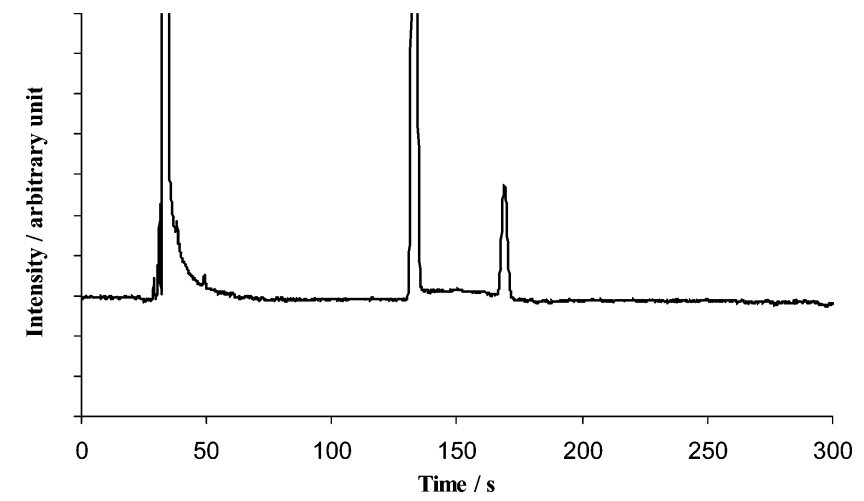

Figure 3. A gas chromatogram of acetylacetone in methylene chloride expanded to illustrate both the static and the dynamic nature of the material.

the time scale of the chromatography. Interconversion between the two tautomers of acetylacetone is slow in the gas phase but occurs readily in the liquid phase. ${ }^{33}$ Despite this, low-temperature HPLC studies ${ }^{34}$ showed it is possible to separate the two tautomers even in the liquid phase. A gas chromatographic trace of acetylacetone in methylene chloride is illustrated in Figure 3. The enol form predominates at equilibrium (retention time $130 \mathrm{~s}$ ). The trace is expanded to illustrate the keto form, which is the sharp peak at approximately $160 \mathrm{~s}$, and a broad rather featureless absorption between the two pure tautomers. The relative intensity of the peaks is in perfect agreement with the studies by Briegleb and Strohmeier ${ }^{26}$ of the composition of the equilibrium mixture in the gas phase. The sharpness of both of these peaks confirms that tautomerism is relatively slow on the time scale of the chromatogram. The broad relatively featureless contribution to the relative intensity between the two peaks is due to a portion of the acetylacetone that has tautomerized during the chromatography. This behavior has been observed and studied previously. ${ }^{35}$ We have confirmed this interpretation with our own GC-MS studies. The mass spectra obtained for the two sharp peaks and at intermediate times were consistent with acetylacetone $(\mathrm{m} / \mathrm{z}, 100$ parent ion, major fragments at $m / z 85$ and 43). Differences in the fragmentation pattern and fragment intensity were observed in the two sharp peaks; these were consistent with those previously described and assigned for the two tautomers. ${ }^{35,36}$

Correlation gas chromatography is not a direct method for determining vaporization enthalpies. What is determined directly is the enthalpy of transfer from the condensed phase of the column to the gas phase, $\Delta_{\sin }{ }^{\mathrm{g}} H_{\mathrm{m}}$. A value of $\Delta_{\mathrm{sln}}{ }^{\mathrm{g}} H_{\mathrm{m}}$ is obtained by plotting $\ln \left(1 / t_{\mathrm{a}}\right)$, where $t_{\mathrm{a}}$ represents the time each analyte spends on the column, against reciprocal temperature, $\mathrm{K}^{-1}$. The reciprocal of $t_{\mathrm{a}}$ is proportional to the vapor pressure of each analyte on the stationary phase of the column at a particular temperature. Once evaluated, enthalpies of transfer measured experimentally are correlated to known vaporization enthalpies measured by some other means. The vaporization enthalpy of the target is obtained from the correlation equation. Selection of the reference compounds is crucial in the evaluation. Generally, reference compounds are chosen with the same type and number of functional groups as the target compound. Some flexibility is possible in certain cases where it has been demonstrated empirically that functional group substitution still provides suitable correlations. For example, good correlations have previously been obtained when an ester group is substituted for a ketone as in this study. ${ }^{37} \mathrm{~A}$ rationale for this has recently been reported. ${ }^{38}$

The vaporization enthalpies of only a limited number of diketones are available as reference compounds for 2,4-pentanedione. Reference compounds for the enol, (Z)-3-hydroxy-3-penten-2-one, are also problematic. Many enolic compounds also exist in equilibrium with their diketone form. Literature vaporization enthalpies measured on the mixture suffer from the same ambiguities as those associated with acetylacetone. Aromatic enols such as the acetylphenols are good models for acetylacetone but to obtain a spread of retention times, several hydroxyketones and hydroxyesters have also been used as models for the enol form. As a test of whether these compound would serve as reliable models, the vaporization enthalpy of 2,2,6,6-tetramethyl-3,5-heptanedione was measured first. 2,2,6,6-Tetramethyl-3,5-heptanedione also exists in equilibrium with an enol form, (Z)-5-hydroxy-2,2,6,6-tetramethylhept-4-en-3-one. However, the enol form in this case predominates to the extent of $98 \%$. Any enthalpy of mixing term should cause only a minor perturbation to the vaporization enthalpy of the pure enol. The vaporization enthalpies of 2,2,6,6-tetramethyl3,5-heptanedione, $(59.5 \pm 0.2) \mathrm{kJ} \cdot \mathrm{mol}^{-1}$, as well as a series of other substituted acetylacetones have been measured. ${ }^{39}$

A summary of the results obtained by plotting $\ln \left(1 / t_{\mathrm{a}}\right)$ verus $1 / T$ for the series of enols used as standards for (Z)-5-hydroxy2,2,6,6,-tetramethylhept-4-en-3-one are given in Table 4. Plots of $\ln \left(1 / t_{\mathrm{a}}\right)$ versus $1 / T$ resulted in linear correlations with correlation coefficients $\left(r^{2}>0.99\right)$. The equation at the bottom of Table 4, eq 6, summarizes the correlation observed between 
TABLE 4: Enthalpies of Transfer and Vaporization Enthalpies Obtained for (Z)-5-Hydroxy-2,2,6,6,-tetramethyl-4-hepten-3-one

\begin{tabular}{|c|c|c|c|c|c|}
\hline compd & slope & intercept & $\begin{array}{c}\Delta_{\mathrm{sIn}}{ }^{\mathrm{g}} H_{\mathrm{m}}(387 \mathrm{~K}) / \\
\mathrm{kJ} \cdot \mathrm{mol}^{-1}\end{array}$ & $\begin{array}{c}\Delta_{\mathrm{l}}^{\mathrm{g}} H_{\mathrm{m}}(298.15 \mathrm{~K}) / \\
\mathrm{kJ} \cdot \mathrm{mol}^{-1} \text { (lit.) }\end{array}$ & $\begin{array}{c}\Delta_{\mathrm{l}}^{\mathrm{g}} H_{\mathrm{m}}(298.15 \mathrm{~K}) / \\
\mathrm{kJ} \cdot \mathrm{mol}^{-1}(\text { calcd })\end{array}$ \\
\hline ethyl 3-hydroxyhexanoate & -5214.0 & 12.30 & 43.347 & 61.9 & 61.8 \\
\hline (Z)-5-hydroxy-2,2,6,6-tetramethyl-4-hepten-3-one & -5221.7 & 12.24 & 43.411 & & $61.9 \pm 0.8$ \\
\hline$o$-hydroxyacetophenone & -5046.6 & 11.60 & 41.955 & 59.6 & 59.6 \\
\hline methyl 2-hydroxybenzoate & -5233.5 & 1190 & 43.509 & 62.0 & 62.0 \\
\hline ethyl 2-hydroxybenzoate & -5600.8 & 12.42 & 46.563 & 66.5 & 66.8 \\
\hline$p$-hydroxyacetophenone & -6761.6 & 14.45 & 56.213 & 82.5 & 81.9 \\
\hline methyl 4-hydroxybenzoate & -6897.0 & 14.70 & 57.339 & 83.1 & 83.6 \\
\hline
\end{tabular}

TABLE 5: Enthalpy of Transfer and Vaporization Enthalpy Obtained for (Z)-4-Hydroxy-3-penten-2-one

\begin{tabular}{|c|c|c|c|c|c|}
\hline compd & slope & intercept & $\begin{array}{c}\Delta_{\mathrm{sln}}{ }^{\mathrm{g}} H_{\mathrm{m}}(359 \mathrm{~K}) / \\
\mathrm{kJ} \cdot \mathrm{mol}^{-1}\end{array}$ & $\begin{array}{c}\Delta_{\mathrm{l}}^{\mathrm{g}} H_{\mathrm{m}}(298.15 \mathrm{~K}) / \\
\mathrm{kJ} \cdot \mathrm{mol}^{-1} \text { (lit.) }\end{array}$ & $\begin{array}{c}\Delta_{\mathrm{l}}^{\mathrm{g}} H_{\mathrm{m}}(298.15 \mathrm{~K}) / \\
\mathrm{kJ} \cdot \mathrm{mol}^{-1}(\mathrm{calcd})\end{array}$ \\
\hline 3-hydroxybutanone & -3358.8 & 10.092 & 27.92 & 48.7 & 48.7 \\
\hline (Z)-4-hydroxy-3-penten-2-one & -3703.9 & 10.520 & 30.79 & & $50.8 \pm 0.6$ \\
\hline ethyl 2-hydroxypropanoate & -3942.7 & 10.977 & 32.78 & 52.5 & 52.3 \\
\hline 4-hydroxy-4-methyl-2-pentanone & -3998.0 & 10.914 & 33.24 & 52.3 & 52.6 \\
\hline ethyl 3-hydroxybutanoate & -4516.7 & 11.712 & 37.55 & 55.9 & 55.8 \\
\hline ethyl 3-hydroxyhexanoate & -5476.8 & 13.020 & 45.53 & 61.9 & 61.6 \\
\hline o-hydroxyacetophenone & -3358.8 & 10.092 & 43.34 & 59.6 & 60.0 \\
\hline
\end{tabular}

$$
\Delta_{\mathrm{l}}^{\mathrm{g}} H_{\mathrm{m}}(298.15 \mathrm{~K}) / \mathrm{kJ} \mathrm{mol}^{-1}=(0.734 \pm 0.021) \Delta_{\mathrm{sln}^{\mathrm{g}}}{ } H_{\mathrm{m}}(359 \mathrm{~K})+(28.21 \pm 0.32) ; r^{2}=0.997(\text { eq } 7)
$$

TABLE 6: Enthalpies of Transfer and Vaporization Enthalpies Obtained for 2,4-Pentanedione

\begin{tabular}{|c|c|c|c|c|c|}
\hline compd & slope & intercept & $\begin{array}{c}\Delta_{\mathrm{sln}}{ }^{\mathrm{g}} H_{\mathrm{m}}(328 \mathrm{~K}) / \\
\mathrm{kJ} \cdot \mathrm{mol}^{-1}\end{array}$ & $\begin{array}{c}\Delta_{\mathrm{l}}^{\mathrm{g}} H_{\mathrm{m}}(298.15 \mathrm{~K}) / \\
\mathrm{kJ} \cdot \mathrm{mol}^{-1} \text { (lit.) }\end{array}$ & $\begin{array}{c}\Delta_{\mathrm{l}}^{\mathrm{g}} H_{\mathrm{m}}(298.15 \mathrm{~K}) / \\
\mathrm{kJ} \cdot \mathrm{mol}^{-1}(\text { calcd })\end{array}$ \\
\hline 2,3-butanedione & -3153.8 & 10.493 & 26.22 & 39.0 & 38.9 \\
\hline 2,4-pentanedione & -4305.8 & 12.034 & 35.80 & & $51.2 \pm 2.2$ \\
\hline 2,2,4,4-tetramethylcyclobutanedione & -4603.4 & 12.285 & 38.27 & 54.2 & 54.3 \\
\hline benzoquinone & -4614.4 & 12.111 & 38.36 & 53.4 & 54.4 \\
\hline 2,5-hexanedione & -4800.5 & 12.592 & 39.91 & 57.5 & 56.4 \\
\hline
\end{tabular}

$\Delta_{\mathrm{l}}^{\mathrm{g}} H_{\mathrm{m}}(298.15 \mathrm{~K}) / \mathrm{kJ} \mathrm{mol}^{-1}=(1.283 \pm 0.1) \Delta_{\mathrm{sln}^{\mathrm{g}}}{ }^{\mathrm{g}} H_{\mathrm{m}}(328 \mathrm{~K})+(5.21 \pm 1.1) ; r^{2}=0.989($ eq 8$)$

enthalpies of transfer and literature vaporization enthalpies. A vaporization enthalpy of $(61.9 \pm 0.9) \mathrm{kJ} \cdot \mathrm{mol}^{-1}$ is obtained for (Z)-5-hydroxy-2,2,6,6,-tetramethylhept-4-en-3-one, which compares quite favorably to the literature value, $(59.5 \pm 0.2)$ $\mathrm{kJ} \cdot \mathrm{mol}^{-1}$. The accuracy of the correlation method is highly dependent on the quality of the vaporization enthalpy data used in the correlation. In this instance, we estimate that these two results are probably within the experimental uncertainty of each other and do not attach any particular significance to the small difference observed between measurements of the pure enol (this work) and those of the equilibrium mixture (98\% enol). More importantly, the results confirm that these reference compounds can act as suitable standards for enols.

The results of plots of the $\ln \left(1 / t_{\mathrm{a}}\right)$ verus $1 / T$ for the series of enols used as standards for (Z)-4-hydroxy-3-penten-2-one are reported in Table 5. The results from correlating transfer enthalpies with vaporization enthalpies are given by eq 7 at the bottom of Table 5. Note that a vaporization enthalpy for (Z)-4-hydroxy-3-penten-2-one of $(50.8 \pm 0.6) \mathrm{kJ} \cdot \mathrm{mol}^{-1}$ is obtained for the pure tautomer, in comparison to a value of $43.2 \mathrm{~kJ} \cdot \mathrm{mol}^{-1}$ measured by Irving and Wadsö for the equilibrium mixture. ${ }^{8}$

In a similar fashion, it is also possible to evaluate the vaporization enthalpy of 2,4-pentanedione. A different series of standards are used in this instance. Table 6 summarizes the results of the correlations. The vaporization enthalpy of 2,4-pentanedione measured, $(51.2 \pm 2.2) \mathrm{kJ} \cdot \mathrm{mol}^{-1}$, is within experimental error of that of the enol tautomer.

\section{Conclusions}

A comparison of the vaporization enthalpy measured for pure (Z)-4-hydroxy-3-penten-2-one by correlation gas chromatogra-
TABLE 7: Summary of Standard Molar Enthalpies at $T=$ 298.15 K of the Two Acetylacetone Tautomers ${ }^{a}$

\begin{tabular}{cccc}
\hline compd & $\begin{array}{c}\Delta_{\mathrm{f}} H^{\circ}{ }_{\mathrm{m}}(\mathrm{l}) / \\
\mathrm{kJ} \mathrm{mol}^{-1}\end{array}$ & $\begin{array}{c}\Delta_{\mathrm{l}}^{\mathrm{g}}{ }^{2} H_{\mathrm{m}} / \\
\mathrm{kJ} \mathrm{mol}^{-1}\end{array}$ & $\begin{array}{c}\Delta_{\mathrm{f}} H^{\circ} \mathrm{m}(\mathrm{g}) / \\
\mathrm{kJ} \mathrm{mol}^{-1}\end{array}$ \\
\hline 2,4-pentanedione & $-410.1 \pm 1.2$ & $51.2 \pm 2.2$ & $-358.9 \pm 2.5$ \\
& {$[-416.3 \pm 1.1]$} & {$[41.9 \pm 0.1]$} & {$[-374.4 \pm 1.3]$} \\
(Z)-3-hydroxy- & $-429.0 \pm 1.0$ & $50.8 \pm 0.6$ & $-378.2 \pm 1.2$ \\
3-penten-2-one & {$[-427.6 \pm 1.1]$} & {$[43.2 \pm 0.1]$} & {$[-384.4 \pm 1.3]$}
\end{tabular}

${ }^{a} \Delta_{\mathrm{f}} H_{\mathrm{m}}^{\circ}(T=298.15 \mathrm{~K}, 1,81.4 \%$ enol and $18.6 \%$ diketo $)=-425.5$ $\pm 1.0 \mathrm{~kJ} \mathrm{~mol}^{-1}$. Values in brackets are the previous accepted values, see ref 3 .

phy and that measured by Irving and Wadsö ${ }^{8}$ suggests that the 333 latter measurement did benefit from a nonzero enthalpy of 334 mixing term. The enthalpy difference between the two sets of 335 vaporization enthalpy measurements amounts to $(7.6 \pm 0.6) \quad 336$ $\mathrm{kJ} \cdot \mathrm{mol}^{-1}$. With use of the same enthalpy difference between 337 liquid acetylacetone tautomers as Hacking and Pilcher, ${ }^{4,13}$ the 338 enthalpy difference between pure tautomers in the absence of 339 $\Delta_{\mathrm{k}, \mathrm{e}} H_{\text {mix }}$ is now calculated to be $(-18.9 \pm 0.7) \mathrm{kJ} \cdot \mathrm{mol}^{-1}$. From 340 the concentrations of enol and diketo forms present at equilib- 341 rium, new enthalpies of formation of liquid enol, $(-429 \pm 1.0) \quad 342$ $\mathrm{kJ} \cdot \mathrm{mol}^{-1}$, and liquid diketone, $(-410.1 \pm 1.2) \mathrm{kJ} \cdot \mathrm{mol}^{-1}$, are 343 calculated. Similarly, this results in new gas enthalpies of 344 formation of the enol, $(-378.2 \pm 1.2) \mathrm{kJ} \cdot \mathrm{mol}^{-1}$, and diketone, 345 $(-358.9 \pm 2.5) \mathrm{kJ} \cdot \mathrm{mol}^{-1}$. These results are summarized in Table 346 7. As can be seen in this table, the new values are significantly 347 different from those previously accepted, the greatest difference 348 occurring in the gas-phase enthalpy of formation of 349 2,4-pentanedione $\left(15.5 \mathrm{~kJ} \mathrm{~mol}^{-1}\right)$.

A comparison of the new gas-phase enthalpies of formation of the two tautomers results in a difference of $(-19.3 \pm 2.8)$ $\mathrm{kJ} \cdot \mathrm{mol}^{-1}$, in excellent agreement with the NMR value reported

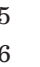
(as

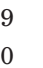
(1) is (n) 
F J. Phys. Chem. B PAGE EST: 5.8

by Folkendt et al., ${ }^{19}(19.5 \pm 0.75) \mathrm{kJ} \cdot \mathrm{mol}^{-1}$. The Folkendt et al. ${ }^{19}$ study appears to have gone unnoticed by thermochemists working in the field. ${ }^{40}$ This is surprising in view of the unambiguous assignment of resonances associated with the keto and enol forms as compared with similar assignments with IR, UV, and photoelectron spectroscopy. Even as late as 1993, the earlier IR value ${ }^{16}$ of $10 \mathrm{~kJ} \mathrm{~kJ} \cdot \mathrm{mol}^{-1}$ has been cited as the gasphase enthalpy difference between tautomers. ${ }^{41}$

The results of this study have several further implications. Revision of the enthalpies of formation of acetylacetone, although small, affects the enthalpies of formation of the various organometallic complexes that have been studied and the metal to oxygen bond strengths that have been derived. In addition, it also calls into question the values measured for the vaporization enthalpies of other $\beta$-diketones and $\beta$-ketoesters that have appreciable concentrations of both tautomers present in the condensed state and the formation enthalpies calculated from them. ${ }^{39,40}$

Acknowledgment. J.S.C. would like to thank the Research Board of the University of Missouri and M.T. would like to thank MEC/SEUI, FPU AP2002-0603, Spain for financial support and M.V.R. would like to thank the Ministerio de Educación Ciencia y Deportes of Spain for a PR2004-0111 grant.

Supporting Information Available: Tables S1 and S2 containing a summary of the vaporization enthalpies of the standards used or derived from sublimation enthalpies available in the literature; Table S3 summarizing the temperature adjustments necessary to convert fusion enthalpies to $T=298.15 \mathrm{~K}$ of the solid standards; Table S4 summarizing how vaporization enthalpy was calculated from the sublimation enthalpy of the solid standards; Tables S5, S7, S8, and S9 containing the retention times of the compounds studied; and Table S6 summarizing the correlation gas chromatography experiments used to evaluate the vaporization enthalpies of $o$-hydroxyacetophenone and methyl $p$-hydroxybenzoate also used as standards in these experiments. This material is available free of charge via the Internet at http://pubs.acs.org.

\section{References and Notes}

(1) $\Delta_{\mathrm{f}} H_{\mathrm{m}}^{\circ}(1,298.15 \mathrm{~K})=-533.9 \mathrm{~kJ} \cdot \mathrm{mol}^{-1}$ : Kharasch, M. S. J. Res. Natl. Bur. Stand. 1929, 2, 359

(2) $\Delta_{\mathrm{f}} H_{\mathrm{m}}^{\circ}(1,298.15 \mathrm{~K})=-443.9 \pm 8.0 \mathrm{~kJ} \cdot \mathrm{mol}^{-1}$ : Vilcu, R.; Perisanu, S. Rev. Roum. Chim. 1979, 24, 237-243.

(3) Nicholson, G. R. J. Chem. Soc. 1957, 2431 1017.

(4) Hacking, J. M.; Pilcher, G. J. Chem. Thermodyn. 1979, 11, 1015229

(5) Askonas, C. F.; Daubert, T. E. J. Chem. Eng. Data 1988, 33, 225-

(6) Raviprasad, A.; Venkateswara Rao, K. J. Chem. Thermodyn. 1985, $17,117-121$. 3211.

(8) Irving, R. J.; Wadsö, I. Acta Chem. Scand. 1970, 24, 589-592.

(9) Melia, T. P.; Merrifield, R. J. Appl. Chem. 1969, 19, 79-82.

(10) Farrar, D. T.; Jones, M. M. J. Phys. Chem. 1964, 68, 1717-1721.

(11) Jones, M. M.; Yow, B. J.; May, W. R. Inorg. Chem. 1962, 1, 166169

(12) Chickos, J. S.; Acree, W. E., Jr. J. Phys. Chem. Ref. Data 2003, $32,519-878$

(13) Reeves, L. Can. J. Chem. 1957, 35, 1351-1365.

(14) Burdett, J. L.; Rogers, M. T. J. Am. Chem. Soc. 1964, 86, 21052109

(15) Allen, G.; Dwek, R. A. J. Chem. Soc. 1966, 161-163.

(16) Powling, J.; Bernstein, H. J. J. Am. Chem. Soc. 1951, 73, 43534356

(17) Sunaga, H.; Irie, M. Giho-Waseda Daigaku Rikogakubu 1996, 24, $25-27$

(18) Hush, N. S.; Livett, M. K.; Peel, J. B.; Willett, G. D. Aust. J. Chem. 1987, 40, 599-609.

(19) Folkendt, M. M.; Weiss-Lopez, B. E.; Chauvel, J. P., Jr.; True, N. S. J. Phys. Chem. 1985, 89, 3347-3352.

(20) Spencer, J. N.; Holmboe, E. S.; Kirshenbaum, M. R.; Firth, D. W.; Pinto, P. B. Can. J. Chem. 1982, 60, 1178-1182.

(21) Nakanishi, H.; Morita, H.; Nagakura, S. Bull Chem. Soc. Jpn. 1977, $50,2255-2261$.

(22) Schweig, A.; Vermeer, H.; Weidner, U. Chem. Phys. Lett. 1974, 26, 229-233.

(23) Burdett, J. L.; Rogers, M. T. J. Phys. Chem. 1966, 70, 939-941.

(24) Mecke, R.; Funck, E. Hydrogen Bonding; Hadzi, D., Ed.; Pergamon Press: London, UK, 1959; p 433; as cited in ref 21.

(25) Strohmeier, W.; Hohne, I. Z. Naturforsch. 1952, 7b, 184-187.

(26) Briegleb, G.; Strohmeier, W. Angew. Chem. 1952, 64, 409-417.

(27) Grossman, P. Z. Phys. Chem (Leipzig) 1924, 109, 305.

(28) Meyer, K. H. Ber. 1911, 44, 1147, 2718.

(29) Saluja, P. P. S.; Peacock, L. A.; Fuchs, R. J. Am. Chem. Soc. 1979, $101,1959-1962$.

(30) Temprado, M.; Chickos, J. S. Thermochim. Acta. Submitted for publication.

(31) Chickos, J. S.; Hanshaw, W. J. Chem. Eng. Data 2004, 49, 77-85 and references cited.

(32) Chickos, J. S. Thermochim. Acta 1998, 313, 19-26.

(33) Conant, J. B.; Thompson, A. F. J. Am. Chem. Soc. 1932, 54, 4044.

(34) Moriyasu, M.; Kato, A.; Hashimoto, Y. Chem. Lett. 1984, 7, 11811184

(35) Skrdla, P. J.; Antonucci, V.; Lindemann, C. J. Chromatogr. Sci. 2001, 39, 431-440.

(36) Zamir, L.; Jensen, B. S.; Larsen, E. Org. Mass Spectrosc. 1969, 2 , $49-61$.

(37) Perisanu, S.; Contineanu, I.; Banciu, M. D.; Liebman, J. F.; Farivar, B. S.; Mullan, M. A.; Chickos, J. S.; Rath, N.; Hillesheim, D. M. Thermochim. Acta 2003, 400, 109-120.

(38) Chickos, J. S.; Zhao, H.; Nichols, G. Thermochim. Acta 2004, 424 , $111-121$

(39) Ribeiro da Silva, M. A. V.; Irving, R. J. Rev. Port. Quim. 1978, $20,36-46$.

(40) Ribeiro da Silva, M. A. V.; Ferrão, M. L. C. C. H.; Jiye, F. J. Chem. Eng. Data 1995, 40, 426-428.

(41) Pilcher, G.; Parchment, O. G.; Hillier, I. H.; Heatley, F. D.; Ribeiro da Silva, M. A. V.; Ferrão, M. L. C. C. H.; Monte, M. J. S.; Jiye, F. J. Phys. Chem. 1993, 97, 243-247.

(42) Zabransky, M.; Ruzicka, V., Jr.; Majer, V.; Domalski, E. S. Heat Capacities of Liquids; Vol. II, Critical Review and Recommended Values; J. Phys. Chem Ref. Data, Monograph 6; American Institute of Physics: Woodbury, NY, 1996. 